\title{
KAJIAN KINERJA TERMINAL BATU AMPAR KOTA BALIKPAPAN
}

\author{
Randha Alief Chikita*1 ${ }^{*}$ Ludfi Djakfar ${ }^{2}$ dan M. Ruslin Anwar ${ }^{3}$ \\ ${ }^{1}$ Mahasiswa / Program Magister / Teknik Sipil / Universitas Brawijaya Malang \\ ${ }^{2,3}$ Dosen / Jurusan Teknik Sipil / Fakultas Teknik / Universitas Brawijaya Malang \\ Jl. MT Haryono 167, Malang 65145, Indonesia \\ Korespondensi : randhaalief2014@gmail.com
}

\begin{abstract}
Batu Ampar Terminal Balikpapan is the only type A passenger terminal in Balikpapan City. The purpose of this study is to determine the operational performance of the terminal at this time and also to determine the level of service in the terminal. The results of this study indicate that for FIFO queue discipline analysis on $A K D P$ and AKAP bus lines, it is known that $\rho<1$ means that there is currently no queue in the terminal. For the analysis of terminal facilities it is known that there are still some terminal facilities that are not yet available from the main facilities and supporting facilities, therefore the need for additional facilities in order to meet the standard of passenger terminal type A. In the next 15 years analysis for traffic intensity value is approaching 1 which means in the future will cause the queue in the terminal, so it is necessary for the improvement of terminal performance. For the service performance with IPA method there are 35 variables that there are 7 variables that enter in quadrant I. In the next step to do analysis to know the priority of handling by using QFD method.
\end{abstract}

Keywords: Batu Ampar Terminal Balikpapan, IPA, terminal performance, QFD

\section{PENDAHULUAN}

Pertumbuhan suatu kota, akan menyebabkan timbulnya pergerakan baik orang maupun barang. Untuk memenuhi kebutuhan tersebut, diperlukan sarana dan prasarana transportasi yang memadai [1]. Transportasi adalah faktor penting untuk menggerakkan perekonomian suatu daerah. Hal ini disebabkan semakin lancar transportasi maka semakin cepat pula pertumbuhan ekonomi suatu daerah [2].

Kebutuhan angkutan umum sangat diperlukan di wilayah perkotaan, hal ini disebabkan penduduk di wilayah perkotaan umumnya sangat padat, sehingga mempunyai mobilitas hidup yang tinggi dalam kegiatannya sehari-hari [3].

Terminal adalah titik tempat penumpang dan barang memasuki dan meninggalkan suatu sistem transportasi [4]. Terminal bukan hanya sekedar dibangun sebagai peralihan dari suatu sistim transportasi ke sistim transportasi yang lain, tetapi harus memikirkan kenyamanan yang antara lain fasilitas utama dan fasilitas penunjang yang memadai [5]. Sesuai dengan fungsi terminal yang berperan dalam menunjang tersedianya jasa transportasi yang sesuai dengan tingkat kebutuhan, maka keberadaan terminal perlu direncanakan dengan baik agar dapat mengefektifkan dan mengoptimalkan kinerja dari terminal [6].

Terminal Batu Ampar merupakan satusatunya terminal tipe A di Balikpapan yang diharapkan dapat memenuhi kebutuhan angkutan umum masyarakat Balikpapan dan sekitarnya, namun dalam kenyataannya masih jauh dari harapan.

Oleh karena itu perlu dilakukan kajian tentang kinerja Terminal Bus Batu Ampar Balikpapan sehingga kriteria terminal sebagai simpul transportasi yang nyaman dan aman bagi pengguna jasa atau user dapat terwujud. Lokasi terminal bisa dilihat pada Gambar 1. 


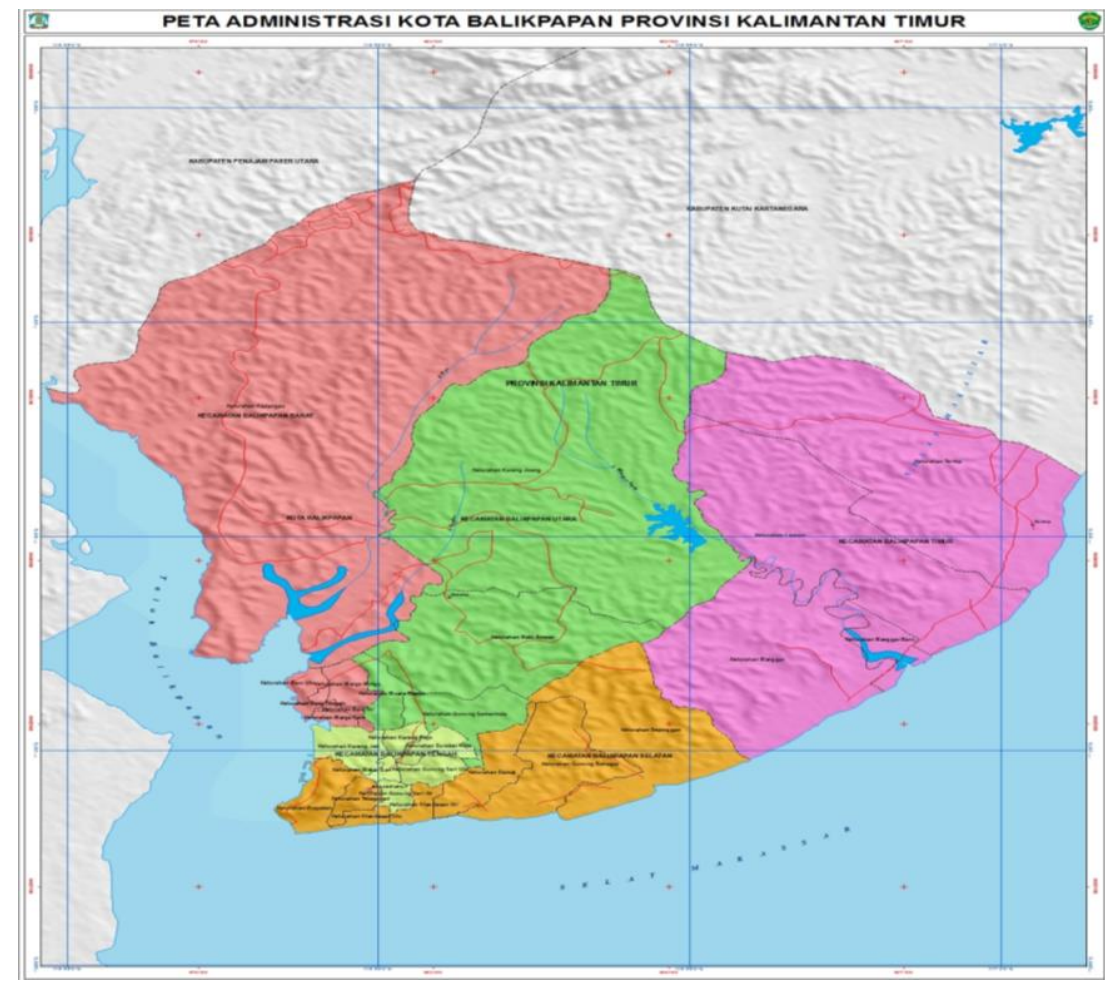

Gambar 1. Lokasi penelitian

\section{METODE PENELITIAN}

Untuk mendapatkan hasil yang diinginkan, maka perlu sebuah acuan dalam pelaksanaan penelitian yang biasa disebut sebagai metode penelitian.

Dalam hal ini perlu dibuat tahapan penelitian. Gambaran tahapan penelitian dapat dilihat pada Gambar 2.

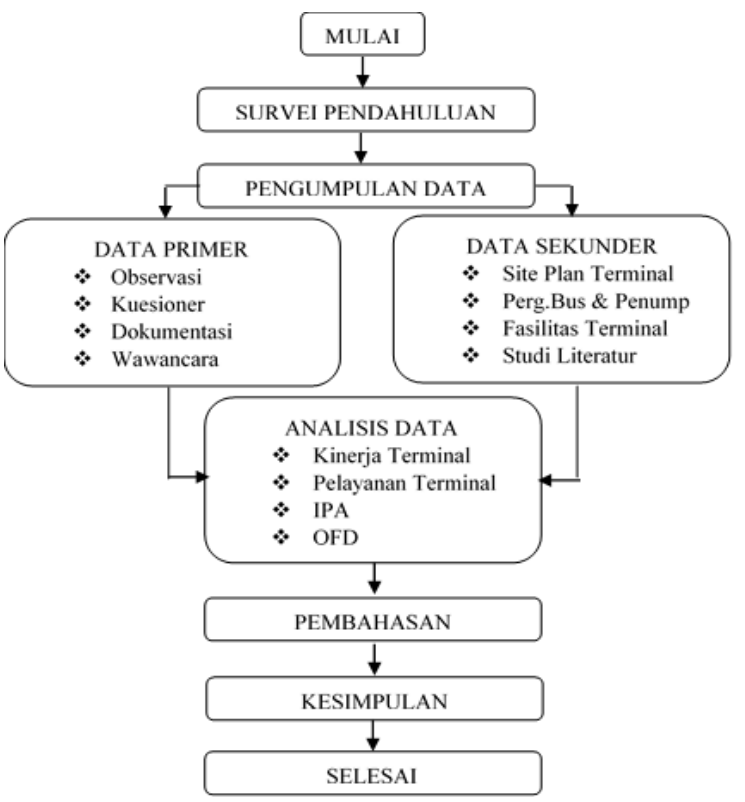

Gambar 2. Diagram alir penelitian

\subsection{Metode Pengumpulan Data}

Pada langkah ini dilakukan pengumpulan data antara lain data primer dan data sekunder. Data yang dikumpulkan dapat bersifat data kualitatif maupun data kuantitatif.

Berdasarkan rumus solvin diperoleh 100 responden.

$$
\mathrm{n}=\frac{\mathrm{N}}{1+\mathrm{Ne}^{2}}
$$

\subsection{Metode Analisa Data}

Dalam penelitian ini digunakan beberapa metode untuk mendapatkan tujuan dari penelitian ini, yaitu antara lain analisis fasilitas terminal dan analisis antrian untuk mengetahui kinerja terminal pada saat ini, sedangkan untuk tingkat pelayanan menggunakan analisis IPA dan analisis QFD.

1.Analisis fasilitas terminal dan analisis antrian untuk mengetahui kinerja terminal saat ini. Analisis antrian sendiri menggunakan disiplin antrian FIFO dengan parameter antara lain, tingkat kedatangan $(\lambda)$, tingkat pelayanan $(\mu)$, intensitas lalu lintas $(\rho)$, jumlah rata-rata kendaraan dalam system $(\mathrm{n})$, panjang antrian rata-rata $(\mathrm{q})$, waktu rata-rata dalam system $(d \overline{)}$ dan waktu tunggu rata-rata dalam antrian (w). 


$$
\begin{array}{ll}
\rho=\frac{\lambda}{\mu} & \bar{w}=\bar{d}-\frac{1}{\mu} \\
\bar{n}=\frac{\rho}{1-\rho} & \bar{q}=\frac{\rho 2}{1-\rho} \\
\bar{d}=\frac{1}{\mu-\lambda} & \bar{h}=\frac{1}{\lambda}
\end{array}
$$

2.Analisis dengan metode IPA untuk mengetahui persepsi pengguna terminal terhadap pelayanan terminal yang dalam hal ini responden pengguna terminal adalah penumpang.

3.Analisis dengan metode QFD dilakukan wawancara dengan kepala UPT terminal untuk memberikan solusi terhadap prioritas penanganan tingkat pelayanan, dalm hal ini yang masuk pada kuadran 1 analisis IPA.

\section{HASIL PEMBAHASAN}

\subsection{Analisa Fasilitas Terminal}

Analisis ini dilakukan untuk mengetahui kelengkapan fasilitas-fasilitas yang ada di Terminal Batu Ampar, apakah telah sesuai dengan standar terminal penumpang tipe A baik dari fasilitas utama maupun dari fasilitas penunjang. Ketersediaan fasilitas Terminal Batu Ampar dapat dilihat pada Tabel 1.

Dilihat dari ketersedian ataupun kelengkapan yang ada di Terminal Batu Ampar baik dari segi fasilitas utama maupun fasilitas penunjang, maka diketahui bahwa masih ada beberapa fasilitas yang belum tersedia di terminal sehingga hal itu perlu untuk lengkapi agar memenuhi kriteria standar fasilitas untuk terminal penumpang tipe $\mathrm{A}$.

Tabel 1. Fasilitas Terminal Batu Ampar

\begin{tabular}{|c|c|c|c|c|}
\hline \multirow{2}{*}{ Ketersedian Terminal Batu Ampar } & \multicolumn{2}{|c|}{ Tersedia } & \multicolumn{2}{c|}{ Tidak Tersedia } \\
\cline { 2 - 5 } & & $\%$ & & $\%$ \\
\hline Fasilitas Utama & 12 & 52 & 11 & 48 \\
\hline Fasilitas Penunjang & 7 & 58 & 5 & 42 \\
\hline
\end{tabular}

\subsection{Analisa Antrian}

Analisis ini dilakukan untuk mengetahui apakah di Terminal Batu Ampar pada saat ini terjadi antrian. Analisis ini sendiri menggunakan disiplin antrian FIFO. Parameter yang digunakan dalam analisis ini, yaitu analisis tingkat pelayanan $(\mu)$, tingkat Kedatangan $(\lambda)$, intensitas lalulintas $(\rho)$, jumlah rata-rata kendaraan dalam system $(n \overline{)}$, panjang antrian rata-rata $(\mathrm{q} \overline{)}$, waktu rata-rata dalam system (d $\overline{)}$ dan waktu tunggu rata-rata dalam antrian $(\mathrm{w})$.

Hasil analisis antrian untuk AKDP jurusan Samarinda - Balikpapan dan Bontang Balikpapan dapat dilihat pada Tabel 2, untuk minibus AKDP jurusan Sepaku/Semoi Balikpapan dapat dilihat pada Tabel 3, sedangkan untuk AKAP jurusan Banjarmasin -

\begin{tabular}{|c|c|c|c|c|c|c|c|c|c|}
\hline \multirow{2}{*}{ Jurusan } & & \multirow{2}{*}{ Hari } & $\lambda$ & $\mu$ & \multirow{2}{*}{$\rho$} & $\mathrm{n}$ & $d$ & w & $\mathrm{q}$ \\
\hline & & & (bus/jam) & (bus/jam) & & Bus & Jam & Jam & Bus \\
\hline \multirow{2}{*}{$\begin{array}{l}\text { Samarinda } \\
\text { Balikpapan }\end{array}$} & \multirow{2}{*}{-} & Senin & 3.0 & 7.00 & 0.43 & 0.75 & 0.25 & 0.11 & 0.32 \\
\hline & & Minggu & 3.0 & 6.00 & 0.50 & 1.00 & 0.33 & 0.17 & 0.50 \\
\hline \multirow{2}{*}{\multicolumn{2}{|c|}{$\begin{array}{l}\text { Bontang } \\
\text { Balikpapan }\end{array}$}} & Senin & 1.0 & 6.00 & 0.17 & 0.20 & 0.20 & 0.03 & 0.03 \\
\hline & & Minggu & 1.0 & 7.00 & 0.14 & 0.17 & 0.17 & 0.02 & 0.02 \\
\hline
\end{tabular}
Balikpapan dapat dilihat pada Tabel 4.

Tabel 2. Kapasitas pelayanan AKDP

Tabel 3. Kapasitas pelayanan minibus AKDP

\begin{tabular}{|c|c|c|c|c|c|c|c|c|}
\hline \multirow{2}{*}{ Jurusan } & \multirow{2}{*}{ Hari } & $\lambda$ & $\mu$ & \multirow{2}{*}{$\rho$} & $\mathrm{n}$ & $\mathrm{d}$ & $\mathrm{w}$ & $\mathrm{q}$ \\
\cline { 3 - 6 } \cline { 6 - 8 } & & (bus/jam) & (bus/jam) & & Bus & Jam & Jam & Bus \\
\hline $\begin{array}{c}\text { Sepaku/Semoi }- \\
\text { Balikpapan }\end{array}$ & Senin & 1.0 & 2.00 & 0.50 & 1.00 & 1.00 & 0.50 & 0.50 \\
\cline { 2 - 7 } & Minggu & 1.0 & 2.00 & 0.50 & 1.00 & 1.00 & 0.50 & 0.50 \\
\hline
\end{tabular}


Tabel 4. Kapasitas pelayanan AKAP

\begin{tabular}{|c|c|c|c|c|c|c|c|c|c|}
\hline \multirow{2}{*}{ Jurusan } & & \multirow{2}{*}{ Hari } & $\lambda$ & $\mu$ & \multirow{2}{*}{$\rho$} & $\mathrm{n}$ & $\mathrm{d}$ & $\mathrm{w}$ & $\mathrm{q}$ \\
\hline & & & (bus/jam) & (bus/jam) & & Bus & Jam & Jam & Bus \\
\hline \multirow{2}{*}{$\begin{array}{l}\text { Banjarmasin } \\
\text { Balikpapan }\end{array}$} & & Senin & 1.0 & 7.00 & 0.14 & 0.17 & 0.17 & 0.02 & 0.02 \\
\hline & & Minggu & 1.0 & 5.00 & 0.20 & 0.25 & 0.25 & 0.05 & 0.05 \\
\hline
\end{tabular}

Dari analisis antrian yang dilakukan diketahui untuk kondisi terminal pada saat ini tidak terjadi antrian, hal ini karena dari analisis antrian diketahui bahwa tingkat kedatangan lebih kecil dari tingkat pelayanan, sehingga nilai intensitas lalu lintas masih dibawah angka $1(\rho>1)$.

Pada prediksi jumlah penumpang untuk 15 tahun mendatang dapat dilihat pada Tabel 5. Berdasarkan tingkat pertumbuhan PDRB (Produk Domestik Regional Bruto) kota Balikpapan, yaitu $4.08 \%$ maka peningkatan jumlah penumpang pada akhir tahun 2031 dapat di prediksi dengan rumus $\mathrm{Pt}=\mathrm{P} 0(1+\mathrm{r}) 2$, sehingga didapatkan untuk penumpang yang berangkat dari Terminal Batu Ampar adalah 404.446 penumpang, sedangkan untuk yang datang atau turun ke terminal batu Ampar adalah 430.203 penumpang.

Pada Tabel 6 diketahui intensitas lalu lintas untuk 15 tahun mendatang. Berdasarkan analisis antrian untuk 15 tahun mendatang diperlukan adanya peningkatan kinerja terminal, hal itu karena berdasarkan analisis 15 tahun mendatang diketahui bahwa niali intensitas lalu lintas di Terminal Batu Ampar mendekati angka 1, yang artinya hal itu akan dapat menyebabkan antrian di terminal karena tingkat kedatangan lebih besar daripada tingkat pelayanan.

Tabel 5. Prediksi jumlah penumpang 15 tahun

\begin{tabular}{|c|c|c|c|c|c|c|c|}
\hline \multirow{2}{*}{ No } & \multirow{2}{*}{ Tahun } & \multicolumn{2}{|c|}{ Penumpang } & \multirow{2}{*}{ No } & \multirow{2}{*}{ Tahun } & \multicolumn{2}{c|}{ Penumpang } \\
\cline { 3 - 4 } \cline { 7 - 8 } & & Berangkat & Tiba & & & Berangkat & Tiba \\
\hline 1 & 2016 & 222010 & 236137 & 9 & 2024 & 305711 & 325164 \\
\hline 2 & 2017 & 231068 & 245771 & 10 & 2025 & 318184 & 338431 \\
\hline 3 & 2018 & 240496 & 255799 & 11 & 2026 & 331166 & 352239 \\
\hline 4 & 2019 & 250308 & 266235 & 12 & 2027 & 344677 & 366610 \\
\hline 5 & 2020 & 260520 & 277098 & 13 & 2028 & 358740 & 381568 \\
\hline 6 & 2021 & 271150 & 288403 & 14 & 2029 & 373377 & 397136 \\
\hline 7 & 2022 & 282212 & 300170 & 15 & 2030 & 388610 & 413339 \\
\hline 8 & 2023 & 293727 & 312417 & 16 & 2031 & 404466 & 430203 \\
\hline
\end{tabular}

Tabel 6. Intensitas lalu lintas untuk 15 tahun mendatang

\begin{tabular}{|c|c|c|c|c|}
\hline \multirow{2}{*}{ Tahun } & \multicolumn{5}{|c|}{ TRAYEK } \\
\cline { 2 - 5 } & $\begin{array}{l}\text { Samarinda } \\
\text { Balikpapan }\end{array}$ & $\begin{array}{l}\text { Bontang } \\
\text { Balikpapan }\end{array}$ & $\begin{array}{l}\text { Sepaku/Semoi } \\
\text { Balikpapan }\end{array}$ & $\begin{array}{l}\text { Banjarmasin } \\
\text { Balikpapan }\end{array}$ \\
\hline 2018 & 0.52 & 0.17 & 0.52 & 0.21 \\
\hline 2019 & 0.54 & 0.18 & 0.54 & 0.22 \\
\hline 2020 & 0.56 & 0.19 & 0.56 & 0.23 \\
\hline 2021 & 0.59 & 0.20 & 0.59 & 0.23 \\
\hline 2022 & 0.61 & 0.20 & 0.61 & 0.24 \\
\hline
\end{tabular}




\begin{tabular}{|c|c|c|c|c|}
\hline \multirow[b]{2}{*}{ Tahun } & \multicolumn{4}{|c|}{ TRAYEK } \\
\hline & $\begin{array}{ll}\text { Samarinda } & - \\
\text { Balikpapan }\end{array}$ & $\begin{array}{l}\text { Bontang } \\
\text { Balikpapan }\end{array}$ & $\begin{array}{l}\text { Sepaku/Semoi } \\
\text { Balikpapan }\end{array}$ & $\begin{array}{ll}\text { Banjarmasin } & - \\
\text { Balikpapan } & \end{array}$ \\
\hline 2023 & 0.64 & 0.21 & 0.64 & 0.25 \\
\hline 2024 & 0.66 & 0.22 & 0.66 & 0.26 \\
\hline 2025 & 0.69 & 0.23 & 0.69 & 0.28 \\
\hline 2026 & 0.72 & 0.24 & 0.72 & 0.29 \\
\hline 2027 & 0.75 & 0.25 & 0.75 & 0.30 \\
\hline 2028 & 0.78 & 0.26 & 0.78 & 0.31 \\
\hline 2029 & 0.81 & 0.27 & 0.81 & 0.32 \\
\hline 2030 & 0.84 & 0.28 & 0.84 & 0.34 \\
\hline 2031 & 0.88 & 0.29 & 0.88 & 0.35 \\
\hline 2032 & 0.91 & 0.30 & 0.91 & 0.36 \\
\hline
\end{tabular}

\section{ANALISA IPA}

Hasil analisis Importance Performance Analysis untuk tingkat pelayanan di Terminal Batu Ampar berdasarkan persepsi penumpang dapat dilihat pada Gambar 3.

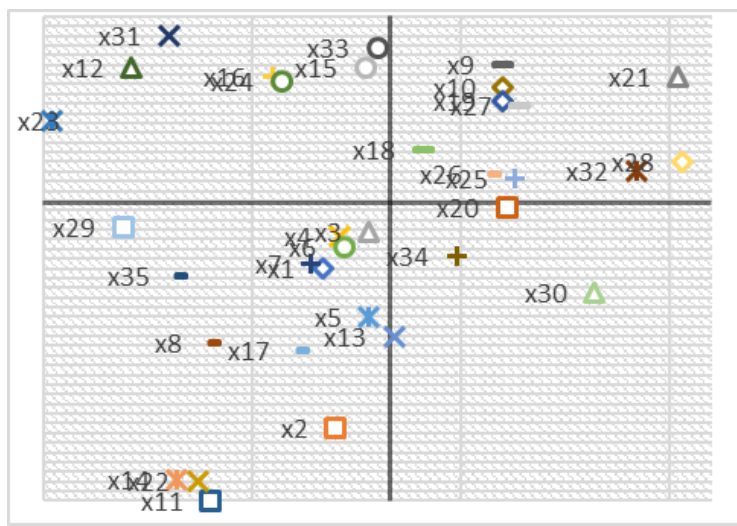

Gambar 3. Hasil analisis IPA

Dilihat pada hasil analisis IPA yang terdapat pada diagram kartesisus maka didapatkan prioritas penanganan pada kinerja tingkat pelayanan di Terminal Batu Ampar.

- Kuadran I (Prioritas Utama) dengan tingkat kepentingan tinggi tapi tingkat kinerjanya rendah, berisi 7 item yaitu area dengan jaringan internet / hotspot area (x23), loket penjualan tiket (x12), fasilitas pengisian baterai / charging corner ( x31), toilet (x16), ruang baca / reading corner (x24), ruang tunggu (x15), dan tempat parkir kendaraan umum dan pribadi (x33).

- Kuadran II (Pertahankan Prestasi) dengan tingkat kepentingan tinggi dan tingkat kinerjanya tinggi, terdapat 10 item, yaitu petugas keamanan (x9), jadwal kedatangan dan keberangkatan (x10), ruang terbuka hijau (x18), rumah makan (x19), area merokok (x21), lampu penerangan jalan (x25), letak jalur pemberangkatan (x26), letak jalur kedatangan (x27), informasi pelayanan (x28), dan tempat naik / turun penumpang (x32).

- Kuadran III (Prioritas Rendah) dengan tingkat kepentingan rendah dan tingkat kinerjanya rendah, terdapat 15 item, yaitu lajur pejalan kaki (x1), jalur evakuasi (x2), alat pemadam kebakaran (x3), pos, fasilitas dan petugas kesehatan $(\mathrm{x} 4)$, informasi fasilitas keselamatan (x5), informasi fasilitas kesehatan (x6), fasilitas keamanan (x7), media pengaduan gangguan keamanan (x8), jadwal kendaraan umum dalam trayek lanjutan dan tidak (x11), kantor penyelenggaraan terminal, ruang kendali dan manajemen (x13), petugas operasional terminal (x14), fasilitas peribadatan/mushola (x17), drainase (x22), informasi angkutan jalan (x29), dan ruang ibu menyusui (x35).

- Kuadran IV (Berlebihan) dengan tingkat kepentingan rendah tapi tingkat kinerjanya tinggi, terdapat 3 item yang terdiri dari pos, fasilitas dan petugas kebersihan (x20), tempat penitipan barang (x30), dan fasilitas penyandang cacat / difabel (x34).

\section{ANALISA QFD}

Dari hasil analisis QFD didapatkan prioritas penanganan berdasarkan nilai normalized contribution, prioritas penanganan dapat dilihat pada Gambar 4. 


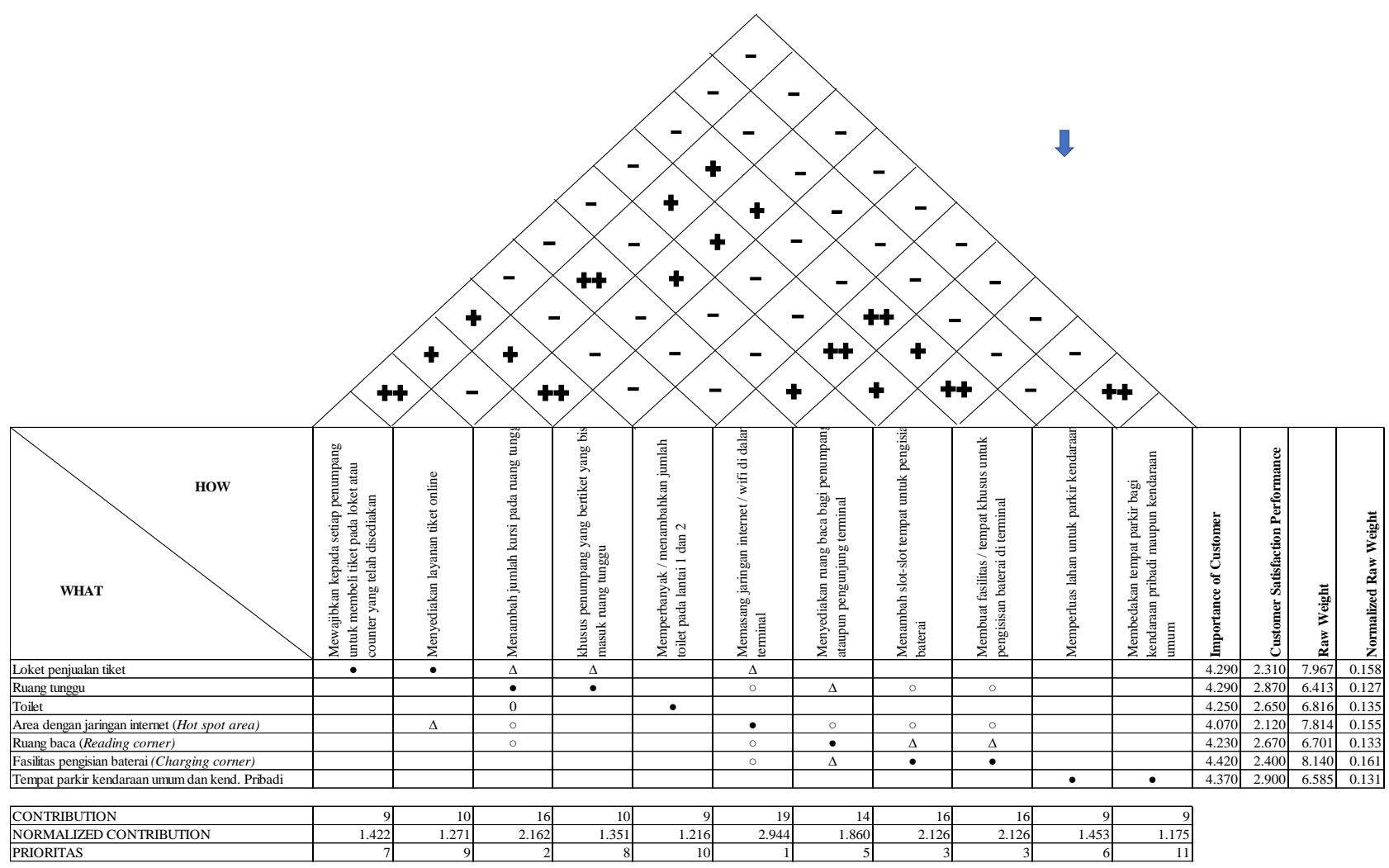

Gambar 4. House of quality

1. Memasang jaringan internet/wifi di dalam terminal (2.944).

Hal ini menjawab rendahnya kepuasan pengunjung terminal terhadap kinerja area dengan jaringan internet (hotspot area). Dengan memasang ajringan internet atau wifi maka itu akan memberikan kenyaman serta kepuasan bagi penumpang ataupun pengunjung yang menggunakan terminal.

2. Menambah jumlah kursi pada ruang tunggu (2.162)

Hal ini akan menjawab rendahnya kepuasan pengunjung terhadap kualitas ruang tunggu. Dengan menambahkan jumlah kursi pada ruang tunggu terminal maka tidak ada lagi penumpang maupun pengunjung terminal yang berdiri pada saat menunggu bus maupun sekedar menjemput keluarga.

3. Menambah slot-slot untuk tempat pengisian baterai (2.126).

Hal ini menjawab rendahnya kepuasan pengunjung bandara terhadap kinerja fasilitas pengisian baterai (charging corner). Menambah slot-slot untuk pengisian baterai di beberapa bagian terminal jelas akan menambah kepuasan penumpang karena akan membuat penumpang maupun pengunjung akanmerasa nyaman dan mudah apabila kehabisan baterai.

4. Membuat fasilitas/tempat khusus untuk pengisian baterai di terminal (2.126).

Hal ini menjawab rendahnya kepuasan pengunjung bandara terhadap kinerja fasilitas pengisian baterai (charging corner). Membuat fasilitas/tempat khusus untuk pengisian baterai diterminal akan membuat kemudahan bagi penumpang ataupun pengungjung untuk mencari tempat pengisian baterai.

5. Menyediakan ruang baca bagi penumpang ataupun pengunjung terminal (1.860).

Hal ini akan menjawab rendahnya kepuasan pengunjung bandara terhadap ruang baca (reading corner). Dengan adanya ruang baca maka penumpang maupun pengguna jasa betah berlama-lama di dalam terminal dan itu akan membuat ramai terminal sehingga akan membuat pengunjung lain tertarik ke terminal.

6. Memperluas lahan untuk parkir kendaraan (1.453).

Hal ini akan menjawab rendahnya kepuasan pengunjung terminal terhadap tempat parkir kendaraan umum dan kendaraan pribadi. Dengan memperluas lahan untuk parkir kendaraan maka akan memudahkan 
pengunjung dalam mencari parkir pada saat keadaan di terminal lagi ramai.

7. Mewajibkan kepada setiap penumpang untuk membeli tiket pada loket atau counter yang telah disediakan (1.422)

Hal ini akan menjawab rendahnya kepuasan pengunjung terminal terhadap loket penjualan tiket. Dengan mewajibkan kepada setiap penumpang untuk membeli tiket pada loket maka hal itu akan memberikan manfaat bagi loket yang telah disediakan yaitu kenyamanan bagi penumpang dan menjadi lebih tertib, sehingga tidak perlu lagi membayar tiket pada saat di dalam bus.

8. Khusus penumpang yang memiliki tiket yang bisa masuk ruang tunggu (1.351).

Hal ini akan menjawab rendahnya kepuasan pengunjung terminal terhadap kinerja ruang tunggu. Dengan mengkhususkan penumpang yang memiliki tiket maka hal itu akan bisa membedakan penumpang bertiket dengan penumpang yang tidak memiliki tiket.

9. Menyediakan layanan tiket online (1.271).

Hal ini akan menjawab rendahnya kepuasan pengunjung terminal terhadap loket pembelian tiket. Dengan adanya layanan tiket online maka pengunjung tidak harus ke terminal untuk mendapatkan tiket bus.

10.Memperbanyak atau menambahkan jumlah toilet pada lantai 1 dan 2 (1.216).

Hal ini akan menjawab rendahnya kepuasan pengunjung terminal terhadap toilet. Dengan memperbanyak atau menambahkan jumlah toilet pada tiap lantai maka pengunjung tidak akan lagi antri hanya untuk sekadar membuang air kecil pada saat kondisi di terminal lagi ramai.

11.Membedakan tempat parkir bagi kendaraan umum dan kendaraan pribadi (1.175).

Hal ini akan menjawab rendahnya kepuasan pengujung terminal terhadap tempat parkir kendaraan umum dan kendaraan pribadi. Dengan melakukan ini maka pengunjung bisa mendapatkan kenyamanan dalam memarkirkan kendaraan tanpa harus bercampur dengan kendaraan umum yang akan membuat penumpang bingung.

\section{KESIMPULAN DAN SARAN 6.1. Kesimpulan}

Maka kesimpulan yang didapatkan sesuai dari tujuan penelitian pada Terminal Batu Ampar, yaitu :

1.Untuk analisa antrian terminal pada saat ini diketahui nilai $(\rho)<1$, sehingga tidak menyebabkan antrian. Sedangkan untuk fasilitas terminal masih perlu dilengkapi karena masih ada beberapa fasilitas yang belum tersedia di terminal.

2.Untuk analisis kinerja tingkat pelayanan didapatkan 7 atribut pelayanan yang mendapatkan perhatian utama dalam hal perbaikan atau peningkatan dari pihak pengelola.

\subsection{Saran}

Dari hasil Analisa dan kesimpulan, diperoleh beberapa saran sebagai berikut :

1.Bagi pengelola Terminal Batu Ampar Balikpapan perlu perbaikan atau peningkatan kinerja terminal sehingga keinginan penumpang ataupun pengguna jasa terminal dalam menggunakan fasilitas terminal semakin meningkat hal itu juga akan berdampak pada peningkatan jumlah penumpang pada Terminal Batu Ampar.

2.Bagi peneliti selanjutnya bisa ditambahkan analisa ekonomi dan analisa parkir.

\section{DAFTAR PUSTAKA}

[1] Hantoro, G., dkk. Karakteristik Pengguna Moda Dari Terminal Bus. Jurnal Ilmiah Semesta Teknika, 7(2), 2004 : 160-170.

[2] Priyambodo., dkk. Analisis Antrean Bus Kota Di Terminal Induk Purabaya Surabaya. Jurnal Gaussian, 1(1), 2012 : 189-198.

[3] Prasetya, D., dkk. Kajian Efektifitas Dan Efisiensi Moda Transportasi Bus Kota Trayek Terminal Purabaya-Perak. Jurnal Swara Bhumi, 1(1). 2016

[4] Morlok, E. K. Pengantar Teknik dan Perencanaan Transportasi. Jakarta: Erlangga. 1984

[5] Utiarahman, A. Analisa Ketersediaan Sarana Dan Prasarana Terminal Bus Pare-Pare. Jurnal Entropi, 2(2). 2007

[6] Widyastuty, A. Kinerja Operasional Pelayanan Terminal Kabupaten Gresik. Jurnal Teknik Waktu, 13(1). 2015 